\title{
Неклассическая логика
}

Non-classical Logic

\section{JEAN-YVES BÉZIAU \\ Many-valuedness from a universal logic perspective}

\author{
Jean-Yves Béziau \\ Federal University of Rio de Janeiro, \\ Largo São Francisco de Paula 1 - Centro, Rio de Janeiro, RJ, 20051-070, Brazil. \\ Brazilian Academy of Philosophy, \\ R. Riachuelo, 303 - Centro, Rio de Janeiro - RJ, 20230-011, Brazil. \\ E-mail: jyb@ufrj.br
}

\begin{abstract}
We start by presenting various ways to define and to talk about many-valued $\operatorname{logic}(\mathrm{s})$. We make the distinction between on the one hand the class of many-valued logics and on the other hand what we call "many-valuedness": the meta-theory of many-valued logics and the related meta-theoretical framework that is useful for the study of any logical systems. We point out that universal logic, considered as a general theory of logical systems, can be seen as an extension of many-valuedness. After a short story of many-valuedness, stressing that it is present since the beginning of the history of logic in Ancient Greece, we discuss the distinction between dichotomy and polytomy and the possible reduction to bivalence. We then examine the relations between singularity and universality and the connection of many-valuedness with the universe of logical systems. In particular, we have a look at the interrelationship between modal logic, 3-valued logic and paraconsistent logic. We go on by dealing with philosophical aspects and discussing the applications of many-valuedness. We end with some personal recollections regarding Alexander Karpenko, from our first meeting in Ghent, Belgium in 1997, up to our last meeting in Saint Petersburg, Russia in 2016.
\end{abstract}

Keywords: many-valued logic, many-valuedness, universal logic, modal logic, 3 -valued logic, paraconsistent logic

For citation: Béziau J.-Y. "Many-valuedness from a universal logic perspective", Logicheskie Issledovaniya / Logical Investigations, 2020, Vol. 26, No. 1, pp. 78-90. DOI: 10.21146/20741472-2020-26-1-78-90 
En toute sobriété j'ai eu de mutliples visions de multiples choses et si je suis arrivé à maintenir ma sérénité c'est en voyant l'unité au-dela de la diversité la cohérence au-delà de l'incohérence. Baron de Chambourcy

\section{Many-Valuedness and Universal Logic}

The aim of this paper is to develop a better understanding of what manyvaluedness is and what universal logic is. Universal logic has emerged as a general theory of logical systems (see [Béziau, 1994] and [Béziau, 2012c]), so it is directly linked to many-valuedness in two different ways:

- Many-valued logics are objects of study of universal logic.

- Many-valuedness, including in particular many-valued logical matrices, is a tool for developing universal logic.

But, as we have pointed out in previous papers (see [Béziau, 2006b] and [Béziau, 2018b]), universal logic is not restricted to a mathematical metatheory, it encompasses also philosophical and methodological questions. Manyvaluedness with its twofold relation with universal logic is a good opportunity to discuss the many virtues of both many-valuedness and universal logic.

\section{Many-Valued Logic(s), Many-Valuedness and Universal Logic}

As for many concepts, such as e.g. human being, number or time, there is not only one and true definition of many-valued logic.

First let us make a distinction between "Many-valued logic" and "Manyvalued logics". Here we are putting quotes because we are talking about the linguistic expressions rather than the notions, for which we, as above, use italics. ${ }^{1}$ Although it has become trendy, following the fashion of pluralism, to put an "s" at the end of everything, a small snake tailing any idea, let us emphasize that we can still sanely and safely make the distinction between plurality and singularity, not to say unity. No doubts that there are many girls, cars, numbers, but we still can, even without being a Platonist, consider the notions of girl, car and number.

There are many different many-valued logics, but nevertheless we can consider the notion of many-valued logic which encompasses all these logics. Although it is rather trivial, it is worth emphasizing that the notion of manyvalued logic is not itself a logic, in the same way that the notion of girl is not

\footnotetext{
${ }^{1}$ About the notion of notion, see Béziau, 2018a.
} 
itself a girl, by contrast to the notion of notion which can itself be considered as a notion.

To conceptualize what a girl is, we need a general theory of psychology, zoology, archaeology... Of course we can also give a first idea, as stressed by Quine (cf. Quine, 1960), just by ostentation, pointing at and/or focusing on a canonical example, such as the Girl from Ipanema. We can indeed do the same with many-valued logic, although less beautifully and musically (see Figure 1).
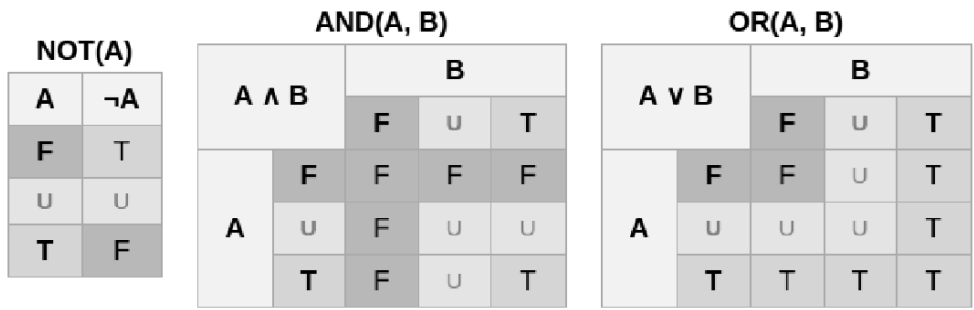

Fig. 1. Definition by Ostentation of the notion of many-valued logic.

That gives a rough idea of what it is. It is necessarily biased, as any tentative to think the general through the particular. But it is fair enough for childish games. If we want to get more scientific, that is another kettle of fish. And if we want to get more philosophical, that is a true cassoulet, not to say feijoada. Let us present three definitions of A MANY-VALUED LOGIC on the basis on which we can go a step further than ostentation:

- A logic which does not reduce to truth and falsity.

- A logic that can be characterized only by a logical matrix of more than 2-values (including or not infinite matrices). ${ }^{2}$

- A logic that can be characterized by any semantics with more than 2 truth-values. ${ }^{3}$

A careful look at these definitions shows that they are pairwise different but not pairwise exclusive. In particular the first does not use the notion of value, the third one uses it but does not use the notion of matrix, by contrast with the second one.

MANY-VALUED LOGIC itself can be considered as

- The class of many-valued logics.

- The meta-theory of many-valued logics.

\footnotetext{
${ }^{2}$ For details see Béziau, 1997.

${ }^{3}$ In this case classical proposotional logic can be considered as a many-valued logic, for details see Béziau, 1997.
} 
- A meta-theoretical tool / framework that is useful for the study of any logical systems.

It is often difficult, not to say artificial, to distinguish between the two first meanings, as in the case of other logics, that is why it is not necessarily useful to introduce two different names. It is also difficult to find a good name for the third meaning. But the expression "MANY-VALUEDNESS" looks pretty good to encompass the 2nd and 3rd above meanings.

The idea of universal logic is to promote a general theory inside which / with which, we can turn conceptualization of logical notions and systems easier. In this sense universal logic is neither a logic, nor a bunch of logics. It is a kind of extension of many-valuedness as just characterized above: it is the metatheory of all logical systems, therefore extending the above 2nd meaning and it is a meta-theoretical framework including the above 3rd meaning.

\section{A Short Short History of Many-Valuedness}

We can say without much exaggeration that many-valuedness exists since the beginning of the world, or better the beginning of the logical world, considering that it is directly connected with Aristotle who is considered himself as the father of logic, as the science of reasoning (Aristotle did not create logic as reasoning, cf. [Béziau, 2010]). This is the famous story of future contingents according to which "Tomorrow will be the end of the world" is neither true, nor false, unless we believe in determinism or apocalypse.

And also without romancising too much we can say that the next step in the story is with Jan Łukasiewicz who, directly influenced by the Stagirite, built a three-valued logic Łukasiewicz, 1920. But Łukasiewicz did much more than that, not only he also built a four-valued logic [Lukasiewicz, 1953, but he developed with other Polish logicians, in particular with Alfred Tarski Lukasiewicz, Tarski, 1930, a whole theory of many-valued logical matrices that is a basic framework and tool for a general theory of logics. At this level we see therefore a strong connection between universal logic and many-valuedness.

This connection was independently promoted by Paul Bernays and Emil Post at approximately the same time. And it is also worth mentioning that many-valued logic did not escape to Charles Sanders Peirce who had a very general view of logic both from a philosophical and mathematical point of views. In particular he was the first to draw three-valued "truth-tables" (see Béziau, 2012a ).

This is of course a very short and synoptic story of many-valuedness. We will not go in more details since our objective here is more to look a the present and the future than the past. But the moral of the story is that many-valuedness 
is present along the whole story of logic and that it is not a crucial difference between traditional logic and modern logic.

\section{Dichotomy and Polytomy}

Before examining the opposition between many-valuedness and bivalent logic closer and if we can reduce or not logicality to bivalence, let us go beyond logic stricto sensu and broaden our horizon to general thinking / conceptualization.

Dichotomy can be found both in the East and the West. In the East we have Taoism, with Yin and her brother Yang, in the West Pythagoras with his table of opposites. Taoism is more radical and interactive: there are only two things from which everything is derived by combination. Pythagoras's table of opposites has at least ten different dichotomic oppositions. But this theory of multiple oppositions was then developed in a very abstract theory of dichotomic oppositions, more abstract than the Chinese one, very logical, connected to the emergence of classical negation, a very powerful tool that can apply to any thing, as we have recently argued in Béziau, 2019.

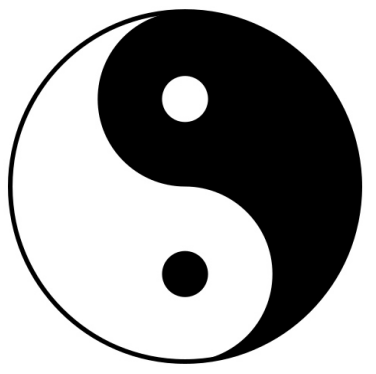

\begin{tabular}{|c|c|}
\hline One & $\begin{array}{c}\text { Many } \\
\text { Left } \\
\text { Female } \\
\text { Oblong } \\
\text { Right }\end{array}$ \\
\cline { 1 - 1 } Male & $\begin{array}{c}\text { Darkness } \\
\text { Bad } \\
\text { Square } \\
\text { Crooked } \\
\text { Light }\end{array}$ \\
\cline { 1 - 1 } Good & Open \\
Straight & Sad \\
Even
\end{tabular}

Fig. 2. Taosim vs. Pythagoricism.

Polytomy can also be seen both in the East and the West. By its own nature polytomy is multiple: it can be $3,4,5$, up to infinity. But what is predominating is small size polytomy: trichotomy, quadritomy, or pentagony. At the religious level we have in India the trimurti with Brahma, Vishnu, Shiva and in the West the trinity of Christianity with The Son, The Father and the Holy Spirit. At a more physical level, we have the theory of four elements in the Occident and the theory of five elements in China.

Vivaldi naturally promoted quadritomy with his masterpiece The Four Seasons. Schopenhauer was also found of a fourfold approach, that he developed at different levels (see [Béziau, 2020]). On the other hand Peirce was very found of trichotomy as well as Robert Blanché, who duplicated it as a colorful hexatomy (see [Blanché, 1966] and [Béziau, 2012d]). One may wonder in which sense this 
symphony of polytomies is part of many-valuedness. In the case of Blanché is hexagon is clearly part of it, if we consider that it can be applied to metalogic (see [Béziau, 2013]).

\section{The Value of Reduction to Bivalence}

If we put aside monotheism, the most impressive reduction of multiplicity is the binary notation. "In the beginning was the word" (John 1:1) can be coded as a sequence of 0 s and $1 \mathrm{~s}$ :

$\begin{array}{lllllll}01001001 & 01101110 & 00100000 & 01110100 & 01101000 & 01100101 & 00100000\end{array}$ 0110001001100101011001110110100101101110011011100110100101101110 0110011100100000011101110110000101110011001000000111010001101000 011001010010000001110111011011110111001001100100

It is less poetic and maybe the meaning of the sentence is lost in some way, but it makes sense for a computer. However we are not (yet) computers and what is good for our understanding is something not tooooooooooooo big, but also not too small. For numbers we use decimal notations, an alphabet has an average of 25 signs and the average of phonemes in a language is 31 .

Reduction in logic can be considered either from a pragmatic viewpoint or an objective viewpoint. A pseudo-Fregean may claim that there are only two real truth-values: truth and falsity, a pseudo-Peircean may say that three values are quite useful. Peirce proved that all binary connectives can be reduced to only one, but it was not for him a reason to use only one.

A three-valued logic like Eukasiewicz logic L3 cannot be defined by a twovalued truth-functional semantics, however it can be defined by a two-valued non-truth functional semantics, the charateristic functions of relatively maximal theories, like many logics. This result can be considered as a typical result of universal logic (see [Béziau, 2012b]). It is a valuable and interesting result but nevertheless something is lost in the reduction, i.e. truth-functionality.

What we can say, against Suszko's reductionist thesis (see da Costa et al., 1996), is that truth-functional semantics helps to give meaning. However we have to be careful with meaning! In standard many-valued matrix semantics the values are divided in two sets: designated and non-designated values. It makes sense to still apply the dichotomy truth/falsity to them. For example in the case of a four-valued matrix semantics with two designated and two nondesignated elements, we can use the terminology: strong truth, weak truth, weak falsity, strong falsity, or necessary truth, possible truth, possible falsity, necessary falsity (see Béziau, 2011).

Moreover many-valued matrices can be used to refine the notion of consequence relation, as it has been done by G. Malinowski [Malinowski, 1990], Shramko and Wansing [Shramko, Wansing, 2011]. 


\section{Singularity vs. Universality}

Let us consider the following truth-table:

\begin{tabular}{|c|c|c|c|c|c|c|c|}
\hline$\multimap$ & 1 & 2 & 3 & 4 & 5 & 6 & 7 \\
\hline 1 & 3 & 7 & 2 & 1 & 4 & 4 & 6 \\
\hline 2 & 1 & 7 & 4 & 2 & 3 & 3 & 1 \\
\hline 3 & 5 & 2 & 3 & 4 & 5 & 2 & 4 \\
\hline 4 & 3 & 2 & 5 & 4 & 3 & 6 & 1 \\
\hline 5 & 2 & 6 & 7 & 3 & 1 & 3 & 1 \\
\hline 6 & 4 & 1 & 4 & 1 & 5 & 7 & 3 \\
\hline 7 & 7 & 3 & 2 & 6 & 2 & 6 & 5 \\
\hline
\end{tabular}

Fig. 3. A Binary Connective in a 7-valued logic.

This is intended to be a truth-table for a binary connective, $\multimap$, in a 7 -valued logic. This connective is very singular, peculiar not to say idiosyncratic. What can we say about it? What can we do with it? And why should we waste our time focusing on it?

We can ask the same questions about any particular individual, whether it is a stone, a tree, a number or a human being. Can we say that the number 5987 has an interest by itself? Maybe yes, maybe not. Some particular numbers are more interesting than others, like the number $\pi$, to give a classical example of celebrity. And some particular connectives are more interesting than other ones like Sheffer stroke, in bivalent classical logic.

The value of a singular connective in many-valued logic really makes sense only from a general perspective and this is true for any singular object of any field. A singular object is singular only in relation with other objects. A universal approach helps to stress singularity. However a particular case can be a starting point.

It is worth to find some general positive and negative results about all finite valued logics. This is very important. For example if we consider Dugundji theorem stating that S5 cannot be characterized by a finite valued logic (cf. [Dugundji, 1940|), then we will not lose our time looking for a possible 256-valued matrix semantics for it. On the other hand one may explore some particular cases in view of a specific goal or based on an intuitive interpretation. One may develop a beautiful 9-valued logic with wonderful applications.

Another methodology is to connect these general investigations with other mathematical properties and theories. This is what Karpenko did making a connection between prime numbers and many-valued matrix semantics (see (Karpenko, 2006|). 


\section{Many-Valuedness and the Universe of Logical Systems}

If we consider many-valuedness as a general tool, in particular logical matrices, it is related to many logics, including bivalent classical logic, in the sense that it can be applied to them at the meta-level, for example for proof of independence of axioms, as Bernays originally did (see Chapter 2 of Béziau, $2012 \mathrm{c}$ ).

Now if we consider many-valuedness as a tool for constructing logical systems, it is related to many other non-classical logics, in particular modal logic, paraconsistent logic, probability logic, fuzzy logic.

Many-valued logic was developed by Eukasiewciz in view of modality, this line of research was in some sense aborted on the one hand due to the negative result of Dugundji [Dugundji, 1940], on the other hand due to the success of possible world semantics. Nevertheless it still makes sense to use many-valuedness to develop modal logic, either using logical matrices or non truth-functional many-valued semantics. In both cases the problem is with self-extensionality, i.e. the failure of the replacement theorem, but this is not necessarily a problem despite the fact that paradoxically modal logic has been qualified as extensional logic.

Three-valued logic has been used for the developement of paraconsistent logic by Asenjo Asenjo, 1966], da Costa and D'Ottaviano D'Ottaviano, da Costa, 1970], Priest [Priest, 1979], Avron [Avron et al., 2018] and Beziau [Béziau, Franceschetto, 2016; Béziau, 2016b.

Asenjo's logic is a logic which is both paraconsistent and 3-valued but not modal, the paraconsistent logic Z Béziau, 2006a is both modal and paraconsistent but not finite-valued and we have investigated logics which are at the same time paraconsistent, modal and many-valued but considering 4-values instead of 3-values (see [Béziau, 2011]).

\section{Philosophy of Many-Valuedness}

In the last 100 years there was a proliferation of logical systems, due in particular to the formalization and mathematization of logic. This is the door open to infinite non-sense. Quine wrote about modern many-valued logic: "Primarily the motivation of these studies has been abstractly mathematical: the pursuit of analogy and generalization. Studied in this spirit, many-valued logic is logic only analogically speaking; it is uninterpreted theory, abstract algebra" Quine, 1960.

Mathematics is nice and can lead us to the sky of ideas, but it is good to always try to have some meaningful constructions, which can help us to land back down to earth. And it is important to work out the interaction between philosophy and mathematics. 
If we say that a proposition is something which is either true or false, formulas of many-valued logic are not propositions. Is this a problem? And then what are they? By contrast we may want to introduce a three-value logic exactly because we believe that we should consider formulas that are neither true nor false as corresponding to propositions.

What happens is that in modern logic people are considering "formulas" in an informal way without asking what they are or/and what they are representing. This is not necessarily a problem, this is the path to abstraction and generalization. But on the one hand it is good to go at a higher level of abstraction, on the other hand to go down to earth to connect to reality.

The idea of universal logic is indeed to consider a structure where a consequence relation acts on objects whose nature is not further specified. These objects can be events, thoughts, information, etc. They can be interpreted in many ways.

It is important to take in account philosophical motivations to develop a mathematical framework. Matrix semantics can look as a non-intuitive, not to say absurd, construct. One may want to build semantics with:

- Formulas having no truth-values.

- Formulas having as value a set of values, e.g. truth and falsity.

These two cases are comically nicknamed respectively gap and glut. It is true that this can be simulated in matrix semantics but simulation is not strictly speaking the same as reality. And although it can make sense to call many-valued the glut case, it is not clear that this makes sense for the gap case.

Let us also stress that a central problem of the philosophy of many-valued logic is how to interpret the additional values. A straightforward interpretation is degrees of truth and degrees of falsity. But in the simplest case, i.e. three-valued logic this does not necessarily make sense in particular due to dissymmetry. The third value is seen most of the time as something at the middle between truth and falsity. It is often called "undetermined" and funny enough it is indeed quite undetermined: it can be considered as designated or non-designated, as neither true nor false, or as both true and false.

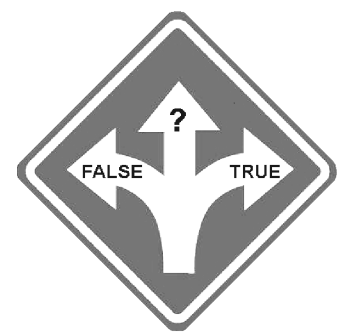

Fig. 4. Indetermination lying at the middle. 


\section{Applications of Many-Valuedness}

We can make a clear distinction between many-valuedness as a meta-theory to study logical systems and many-valuedness as a basis to develop some interesting logical systems that can have useful applications. The first point is quite clear, and we have good examples, the second point is not so obvious, it depends on particular what we really consider as a many-valued logic (cf. our definitions from the first section).

Let us note that there is no many-valued system of logic which really solves the liar paradox (cf. Béziau, 2016a ). It is also not clear that many-valued logic can be applied in case of physics, in particular to Heisenberg's principle of indeterminacy. Paulette Février [Février, 1937] tried to do so many years ago, but she had very few, not to say no, followers.

Applications to computer science also are not clear, computer scientists in fact use another name multiple-valued logic (change of terminology: change of subject?), no to speak about fuzzy logic. Most of the time it is rather something corresponding to many-valuedness or/and algebraic systems rather than to a many-valued logic, excepting the case of the 4-valued logic of Dunn and Belnap (see [Belnap, 1977]), but this logic is also rather a meta-theoretical framework for the theory of computation than an effective system.

\section{Dedication and Personal Recollections}

I am very glad to dedicate this paper to Alexander Karpenko. I met Alexander for the first time at the 1st World Congress on Paraconsistency which took place in Ghent, Belgium, July 30 - August 2, 1997. At this time our discussion was rather limited because I was not speaking Russian and Alexander was not speaking Swiss. We met again the following year at the Stanislaw Jaśkowski Memorial Symposium July 15-18, 1998 in Torun, Poland.

So our encounter started on a paraconsistent basis. But as shown by the paper presented by Alexander in Torun, entitled "Jaśkowski's criterion and threevalued paraconsistent logics" [Karpenko, 1999], he had an interest for a systematic and universal approach, relating different non-classical logics. At this meeting in Torun I presented a talk in some sense diametrically opposed to his paper, because on the one hand my objective was not to work on Jaśkowski's criterion of maximality, but to find an intuitive basis for Jaśkowski's discussive logic, and on the other hand my solution was not based on many-valued matrices, but on possible world semantics (see [Béziau, 2006a]). I started to work on 3 and 4 matrix semantics and paraconsistent logic only later on (see (Béziau, 2011]).

Our 3rd meeting was at Smirnov's Readings - 3rd International Conference - May 24-27, 2001, in Moscow, Russia, which was my first visit to Russia. 
And our further meetings were also all in Russia:

- 4th Smirnov's Reading, May 28-31, 2003, Moscow;

- 6th international conference Logic Today: Developments and Perspectives, June 20-22, 2004, Saint Petersburg;

- 6th Smirnov's Readings, June 17-19, 2009, Moscow;

- Nikolai Vasiliev's Logical Legacy and Modern Logic, October 24-25, 2012, Moscow;

- The 12th international conference Logic Today: Developments and Perspectives, June 22-24, 2016, Saint Petersburg.

We had discussion not limited to logic stricto sensu. Alexander had interest for many topics including arts, in particular poetry, and our friendship developed in the framework of this general perspective. Alexander was the Head of the Department of Logic at the Institute of Philosophy, Russian Academy of Science from 2000 until his death. I think it is important in Russia and elsewhere to have researchers and in particular directors of research like Alexander who have a general perspective and vision.

Acknowledgements. Thanks for useful comments by an anonymous referee.

\section{References}

Asenjo, 1966 - Asenjo, F.G. "A calculus of antinomies", Notre Dame Journal of Formal Logic, 1966, Vol. 7, No. 103, pp. 103-105.

Avron et al., 2018 - Avron, A., Arieli, O., Zamansky, A. Theory of effective propositional paraconsistent logics, College Publication, London, 2018.

Belnap, 1977 - Belnap, N.D. "A useful four-valued logic", in: Modern uses of multiplevalued logic, ed. by M. Dunn. Reidel, Boston, 1977, pp. 8-37.

Béziau, 1994 - Béziau, J.-Y. "Universal logic", in: Logica'94 - Proceedings of the 8th International Symposium, T. Childers and O. Majer (eds.), Prague, 1994, pp. 7393.

Béziau, 1997 - Béziau, J.-Y. "What is many-valued logic ?", in Proceedings of the 27th International Symposium on Multiple-Valued Logic, IEEE Computer Society, Los Alamitos, 1997, pp. 117-121.

Béziau, 2000 - Béziau, J.-Y. "What is paraconsistent logic?", in: Frontiers of paraconsistent logic, Research Studies Press, Baldock, 2000, pp. 95-111.

Béziau, 2004 - Béziau, J.-Y. "Non truth-functional many-valued semantics", in Aspects of Universal Logic, J.-Y. Béziau, A. Costa-Leite and A. Facchini (eds.), University of Neuchâtel, Neuchâtel, 2004, pp. 199-218. 
Béziau, 2006a - Béziau, J.-Y. "The paraconsistent logic Z - A possible solution to Jaśkowski's problem", Logic and Logical Philosophy, 2006, Vol. 15, pp. 99-111.

Béziau, 2006b - Béziau, J.-Y. "13 Questions about universal logic", Bulletin of the Section of Logic, 2006, Vol. 35, pp. 133-150.

Béziau, 2010 - Béziau, J.-Y. "Logic is not logic", Abstracta, 2010, Vol. 6, pp. 73-102.

Béziau, 2011 - Béziau, J.-Y. "A new four-valued approach to modal logic", Logique et Analyse, 2011, Vol. 54, pp. 109-121.

Béziau, 2012a - Béziau, J.-Y. "History of truth-values", in: Handbook of the History of Logic, Vol. 11 - Logic: a history of its central concepts, D.M. Gabbay, F.J. Pelletier and J. Woods (eds.), Elsevier, Amsterdam, 2012, pp. 233-305.

Béziau, 2012b - Béziau, J.-Y. "Paralogics and the theory of valuation", in: Universal Logic: an Anthology - From Paul Hertz to Dov Gabbay, Birkhäuser, Basel, 2012, pp. 361-372.

Béziau, 2012c - Universal Logic: an Anthology - From Paul Hertz to Dov Gabbay, ed. by Béziau J.-Y., Birkhäuser, Basel, 2012.

Béziau, 2012d - Logica Universalis, Special Double Issue on the Hexagon of Opposition, ed. by Béziau J.-Y., 2012, Vol. 6, Issue 1-2.

Béziau, 2013 - Béziau, J.-Y. "The metalogical hexagon of opposition", Argumentos, 2013, Vol. 10, pp. 111-122.

Béziau, 2016a - Béziau, J.-Y. "Trivial dialetheism and the logic of paradox", Logic and Logical Philosophy, 2016, Vol. 25, pp. 51-56.

Béziau, 2016b - Béziau, J.-Y. "Two Genuine 3-Valued Paraconsistent Logics", in: Towards Paraconsistent Engineering, ed. by S.Akama, Springer International Publishing, Cham, 2016, pp. 35-47.

Béziau, 2018a - Béziau, J.-Y. "The Pyramid of Meaning", in: A Coat of Many Colours - D60, J. Ceuppens, H. Smessaert, J. van Craenenbroeck and G. Vanden Wyngaerd (eds.), Brussels, 2018.

Béziau, 2018b - Béziau, J.-Y. "Universal Logic: Evolution of a Project", Logica Universalis, 2018, Vol. 12, pp. 1-8.

Béziau, 2019 - Béziau, J.-Y. "Cats that are not cats", in: Natural Arguments A Tribute to John Woods, D. Gabbay, L. Magnani, W. Park, and A.V. Pietarinen (eds.), College Publications, London, 2019, pp. 49-71.

Béziau, 2020 - Béziau, J.-Y. "Metalogic, Schopenhauer and Universal Logic", in: Mathematics, Logic and Language in Schopenhauer, ed. by Jens Lemanski, Birkhäuser, Basel, 2020.

Béziau, Franceschetto, 2016 - Béziau, J.-Y., Franceschetto, A. "Strong three-valued paraconsistent logics", in: New Directions in Paraconsistent Logic, J.-Y. Béziau, M. Chakraborty and S. Dutta (eds.), Springer, New Delhi, 2016, pp. 131-145.

Blanché, 1966 - Blanché, R. Structures intellectuelles. Essai sur l'organisation systématique des concepts, Vrin, Paris, 1966.

da Costa et al., 1996 - da Costa, N.C.A., Béziau, J.-Y., Bueno, O.A.S. "Malinowski and Suszko on many-valued logics: On the reduction of many-valuedness to twovaluedness", Modern Logic, 1996, Vol. 6, pp. 272-299. 
Cobreros et al., 2014 - Cobreros, P., Egré, P., Ripley D., van Rooij, R. "Foreword: Three-valued logics and their applications", Journal of Applied Non-Classical Logics, 2014, Vol. 24, pp. 1-11.

D'Ottaviano, da Costa, 1970 - D'Ottaviano, I.M.L., da Costa, N.C.A. "Sur un probléme de Jaśkowski", Comptes Rendus de l'Académie des Sciences de Paris, 1970, Vol. 270, pp. 1349-1353.

Dugundji, 1940 - Dugundji, J. "Note on a property of matrices for Lewis and Langford's calculi of propositions", The Journal of Symbolic Logic, 1940, Vol. 5, pp. 150151.

Epstein, 1993 - Epstein, G. Multiple-Valued Logic Design, Institute of Physics Publishing, Bristol, 1993.

Février, 1937 - Février, P. "Les relations d'incertitude d'Heisenberg et la logique", in: Travaux du IXe Congrès International de Philosophie, Vol. 6, Hermann, Paris, 1937, pp. 88-94,

Karpenko, 1999 - Karpenko, A. "Jaśkowski's criterion and three-valued paraconsistent logics", Logc and Logical Philosophy, 1999, Vol. 7, pp. 81-86.

Karpenko, 2006 - Karpenko, A. Lukasiewicz Logics and Prime Numbers, Luniver Press, Beckington, 2006.

Łukasiewicz, 1920 - Łukasiewicz, J. "O logice trjwartosciowej", Ruch Filozoficny, 1920, Vol. 5, pp. 170-171.

Łukasiewicz, 1953 - Łukasiewicz, J. "A system of modal logic", Journal of Computing Systems, 1953, Vol. 1, pp. 111-149.

Łukasiewicz, Tarski, 1930 - Łukasiewicz, J., Tarski, A. "Untersuchungen über den Aussagenkalkül", Comptes Rendus des Séances de la Société des Sciences et des Lettres des Varsovie, Classe III, 1930, Vol. 23, pp. 30-50.

Malinowski, 1990 - Malinowski, G. "Q-consequence operation", Reports on mathematical logic, 1990, Vol. 24, pp. 49-54.

Malinowski, 2007 - Malinowski, G. "Many-valued logic and its philosophy", in: Handbook of the history of logic, Volume 8, D.M. Gabbay, J. Woods (eds.), NorthHolland, Amsterdam, 2007, pp. 13-94.

Priest, 1979 - Priest, G. "The logic of paradox", Journal of Philosophical Logic, 1979, Vol. 8, pp. 219-241.

Quine, 1960 - Quine, W.V.O. Word and Object, MIT Press, Cambridge MA, 1960.

Rescher, 1969 - Rescher, N. Many-Valued Logic, McGraw Hill, New York, 1969.

Shramko, Wansing, 2011 - Shramko, Y., Wansing, H. Truth and Falsehood - An Inquiry inot Generalized Logical Values, Springer, Dordrecht, 2011. 